\title{
A STUDY TO ASSESS THE EFFECTIVENESS OF THE STRUCTURED TEACHING PROGRAM ON KNOWLEDGE OF POSTNATAL DEPRESSION AMONG STAFF NURSES IN SELECTED HOSPITAL AT TUMKUR
}

\author{
Prabhuswami Hiremath1, Vaishali R. Mohite², Gavishiddhayya Salimath ${ }^{3}$, D. Charles Wesley4, Prakash Naregal5, Mahesh Chendake ${ }^{6}$, \\ Manisha Gholap7 , Ujwala R. More ${ }^{8}$ \\ ${ }^{1}$ Lecturer, Department of Psychiatric Nursing, Krishna Institute of Nursing Sciences, Karad. \\ 2Professor and Dean, Krishna Institute of Nursing Sciences, Karad. \\ ${ }^{3}$ Lecturer, Department of Child Health Nursing, KLE Institute of Nursing Sciences, KLE University, Belgaum, Karnataka. \\ ${ }^{4}$ Nursing Supervisor, Al Wakra Hospital, Hamad Medical Corporation, Doha, Qatar. \\ ${ }^{5}$ Lecturer, Department of Child Health Nursing, Krishna Institute of Nursing Sciences, Karad. \\ ${ }^{6}$ Assistant Professor, Department of Medical Surgical Nursing, Krishna Institute of Nursing Sciences, Karad. \\ ${ }^{7}$ Assistant Professor, Department of Medical Surgical Nursing, Krishna Institute of Nursing Sciences, Karad. \\ ${ }^{8}$ Clinical Instructor, Department of Community Health Nursing, Krishna Institute of Nursing Sciences, Karad.
}

\begin{abstract}
The objectives of the study were: 1 . To assess the existing knowledge of staff nurses regarding postnatal depression, 2 . To determine the effectiveness of Structure Teaching Programme (STP) on postnatal depression among Staff Nurses in terms of gain in knowledge scores, 3 . To find out the association between the knowledge of staff nurses with selected demographic variables.

\section{RESEARCH METHODOLOGY}

Evaluator approach was used with one group pre-test post-test design, which is a quasi-experimental design to measure the effectiveness of structure teaching programme on postnatal depression among the staff nurses. The study was conducted in a Shridevi Hospital, Tumkur. Inclusion Criteria were Staff Nurses who are willing to participate in the study, who are available during the period of data collection, Staff Nurses who are qualified in Diploma Nursing. Exclusion Criteria were Staff Nurses Student Nurses who are posted for clinical experience, qualified other than GNM and Staff nurses who are posted in ICU and Emergency ward. The collected data was analysed using descriptive and inferential statistics. The significance of difference between the pre-test and posttest score was found by paired ' $t$ ' test.
\end{abstract}

\section{RESULTS}

In this study, majority 44 (88\%) of the respondents were females. Majority 20 (40\%) of the respondents belongs to the age group of 25-30 years. About 33 (66\%) of the subjects were married. Most $28(56 \%)$ of the respondents belongs to Christianity. All the respondents (50) had completed Diploma in General Nursing and Midwifery Course. The mean pre-test value is 8.22, standard deviation is 6.73 and standard mean error is 0.96 . The mean score is increased in the post test. The mean in the post test is 32.16 and the standard deviation is 6.26. Standard error of mean is 0.89 . The gain in the knowledge based on difference in the pre-test and post-test mean was found to be 23.94 (Improvement). Age is highly significant. Gender, Marital status and Religion are not significant. Intensive programme, current working area and experience in years are significant.

\section{CONCLUSION}

There is a statistically significant improvement in the knowledge among the staff nurses who underwent the structured teaching program on post-natal depression.

\section{KEYWORDS}

Postnatal, Depression, Staff Nurses, Effectiveness.

HOW TO CITE THIS ARTICLE: Hiremath P, Mohite VR, Salimath G, et al. A study to assess the effectiveness of the structured teaching program on knowledge of postnatal depression among staff nurses in selected hospital at Tumkur. J. Evolution Med. Dent. Sci. 2016; 5(62):4337-4341, DOI: $10.14260 /$ jemds/2016/990

\section{INTRODUCTION}

Having a baby is usually a positive experience for mothers and fathers, society expects them to feel happy and fulfilled as they welcome a new life into their world, usually a very happy event, but sometimes it goes wrong to some mothers who

Financial or Other, Competing Interest: None.

Submission 18-06-2016, Peer Review 22-07-2016,

Acceptance 27-07-2016, Published 02-08-2016.

Corresponding Author:

Dr. Prabhuswami Hiremath,

Lecturer,

Department of Psychiatric Nursing,

Krishna Institute of Nursing Sciences,

Karad.

E-mail: prabhuh252003@gmail.com

DOI: $10.14260 /$ jemds $/ 2016 / 990$ feels depressed, which is considered as Post Natal Depression (PND). Postnatal period is the period when women readjusting physiologically and psychologically to motherhood. Emotional responses may be just as intense and powerful for experienced as well as for new mothers. ${ }^{1}$

PND is not easily identified and therefore it often remains undetected. The onset of postpartum depression is gradual and the condition may last for 3-6 months. In some cases, it will persist throughout the first year of the baby's life. ${ }^{2}$ Many mothers begin to feel depressed and hopeless soon after the baby is born.

Postpartum depression can be characterized by all the symptoms of depression including emotional, cognitive and motivational changes; sadness, hopelessness, lack of 
confidence, self-blame, ideas of guilt and worthlessness, difficulties in thinking and making decisions, fatigue, apathy, loss of appetite and weight, disturbed sleep, anxiety, restlessness and suicidal thoughts.

Two prospective studies on pregnant women in the states of Goa and rural South India, detected depressive disorder in $23 \%$ and $16 \%$ respectively with depression persisting six months after child birth in $11-14 \%$ of women. ${ }^{3}$ A study in Karad, Maharashtra, shows prevalence of postnatal depression among primigravid mothers was $13.2 \%{ }^{4}$ Patricia Leahy-Warren et al stated that in their quantitative longitudinal study of 512 first-time mothers that prevalence of PND was $13.2 \%$ at 6 weeks and $9.8 \%$ at 12 weeks. ${ }^{5}$ The recent review by Partrica Leahy et al shown prevalence rates varying from $4.4 \%$ to $73.7 \%$ with the most recent systematic review suggesting a rate of $13 \% .6$ These findings are also similar to other international finding. (Fiona Crottyetal7), Gemma Grier8 stated that postnatal depression affects up to $25 \%$ of all childbearing women; however, its prevalence is often under detected and underdiagnosed. Early screening and intervention are important in the prevention of postnatal depression.

Nurse plays an important role in identifying the depressive symptoms and can initiate treatment with the help of other health team members. It is the nurse who spends maximum time with antenatal and postnatal mother. Nurse, if acts sensitively can prevent much complication arising from postnatal depression. Training on identification of symptoms is required to ensure midwives' competency in psychosocial assessment and management of women experiencing antenatal and postpartum depression. Systemic issues (e.g. time constraints) encountered by midwives need to be addressed to support the delivery of effective emotional care to childbearing women. ${ }^{9}$

\section{OBJECTIVES}

1. To assess the existing knowledge of staff nurses regarding postnatal depression.

2. To determine the effectiveness of structured Teaching Programme on Postnatal depression among Staff Nurses in terms of gain in knowledge scores.

3. To find out the association between the knowledge of staff nurses with selected demographic variables.

\section{RESEARCH METHODOLOGY}

Evaluatory approach was used with one group pre-test posttest design at selected hospital at Tumkur. One group pre-test post-test design was selected for the present study, which is a quasi experimental design to measure the effectiveness of structure teaching programme on postnatal depression among the staff nurses. The study was conducted in a Shridevi Hospital, Tumkur. The sample comprised of 50 diploma staff nurses selected by convenient sampling technique. Inclusion criteria are staff nurses who are willing to participate in the study available during the period of data collection, qualified in diploma nursing. Staff nurses who are posted in emergency ward, who are on leave during data collection, who are qualified other than diploma in nursing were excluded from the study.

Structured knowledge questionnaire was used to collect data which consists of 40 items divided into 5 areas Definition and meaning (5 items), Aetiology (5 items), Clinical features (10 items), Treatment (10 items), Nurses care (10 items). All the items were multiple-choice questions, which has four alternative responses. A score value of (1) was allotted to each correct response. The total knowledge score was 40. The initial draft of structured teaching programme was given to experts from the field along with the tool, 8 experts returned the structure teaching programme with suggestions. The suggestion was to specify the teaching learning activities and made more efforts on preventive measures. The suggestions were accepted and incorporated in the study. Lecture cum discussion method was selected as an appropriate method of teaching staff Nurses. It was planned to teach in groups, since group teaching permits to exchange the views and broadens the knowledge through wider interaction. The study was conducted after obtaining the permission from the concerned authority. The purpose and usefulness of the study was explained to the participants and written consent was taken from them prior to the study to obtain their cooperation. They were also assured of the confidentiality of their responses. Knowledge of staff Nurses was assessed by using structured knowledge questionnaire. The STP was administered. The post-test was conducted on the $7^{\text {th }}$ day. The collected data was analysed using descriptive and inferential statistics. The significance of difference between the pre-test and post-test score was found by paired ' $t$ ' test.

\section{RESULTS}

\section{Section: I Demographic Characteristics}
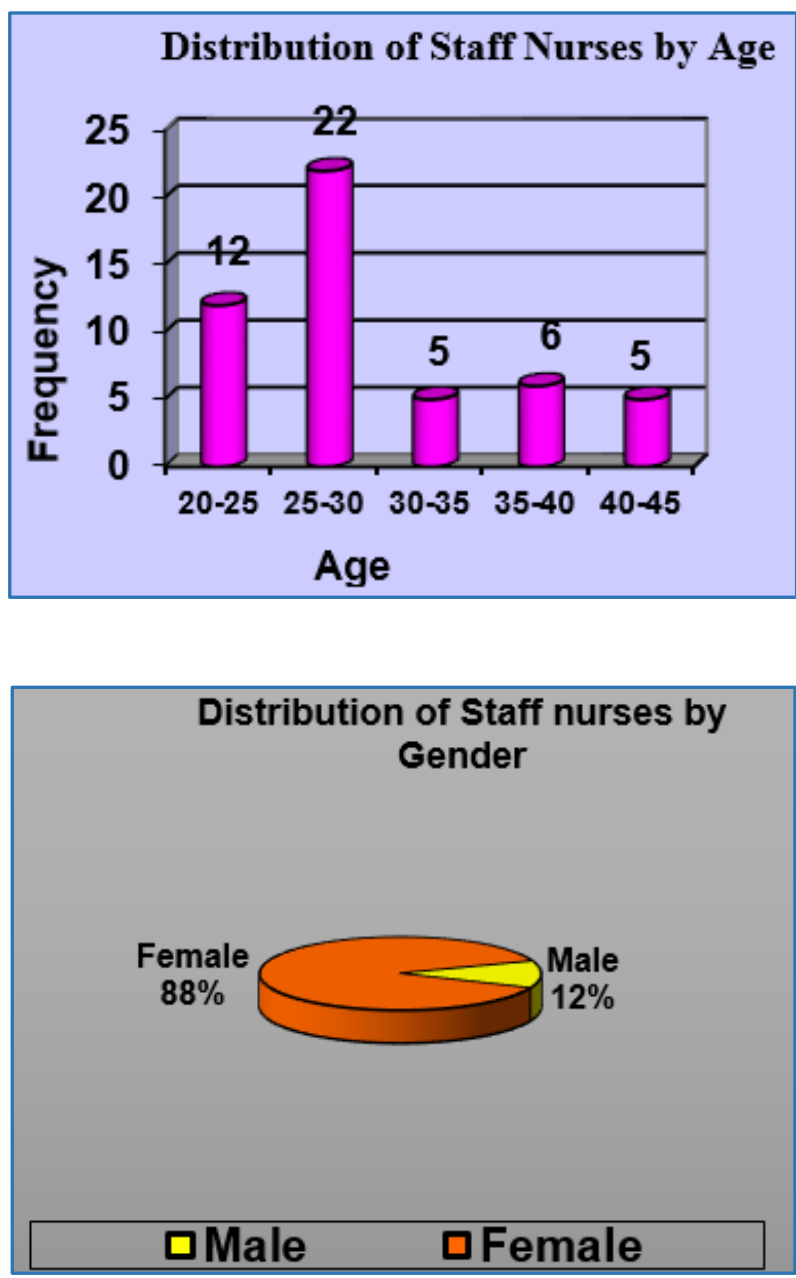


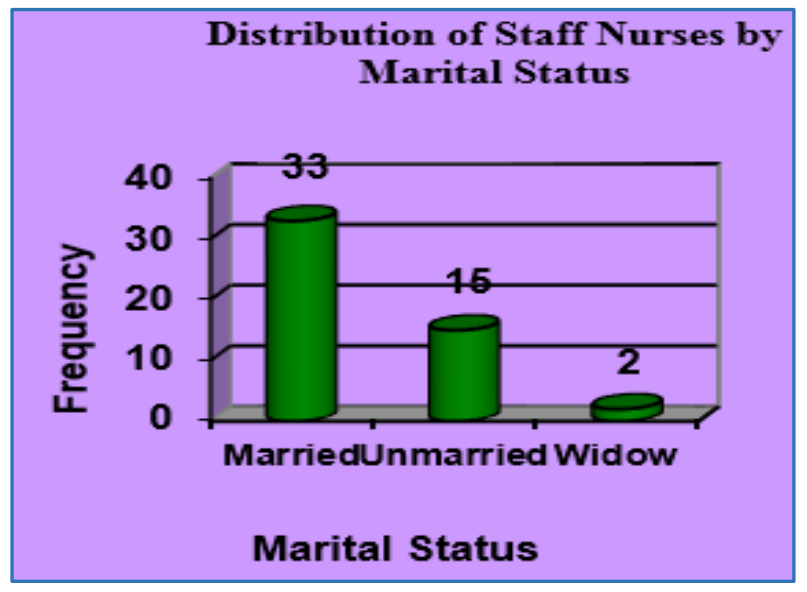

\section{Distribution of Staff nurses by religion}

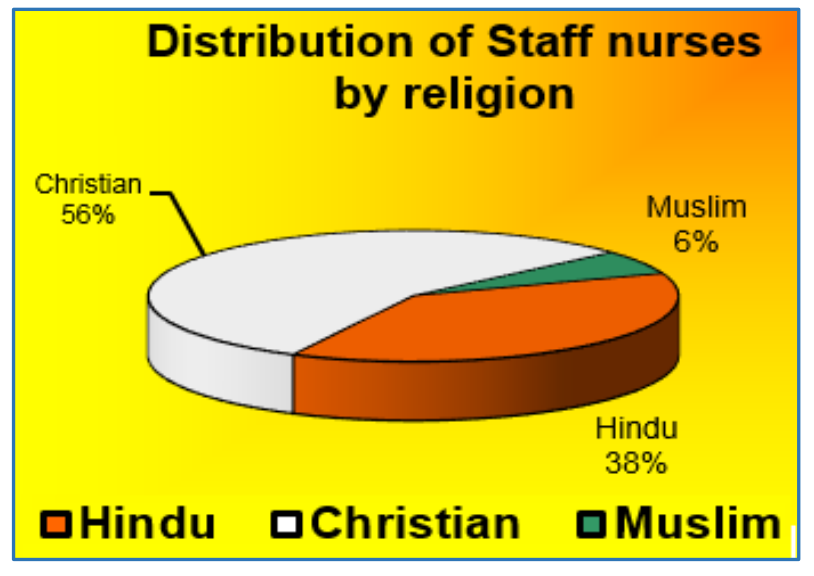

Distribution of Staff Nurses by Professional Experience

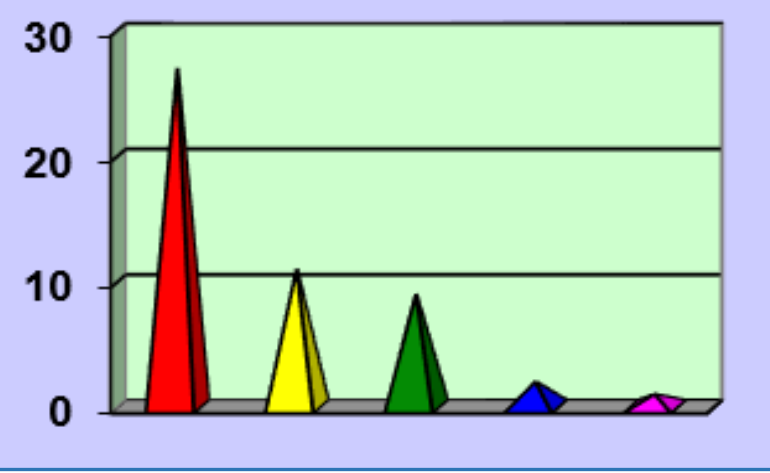

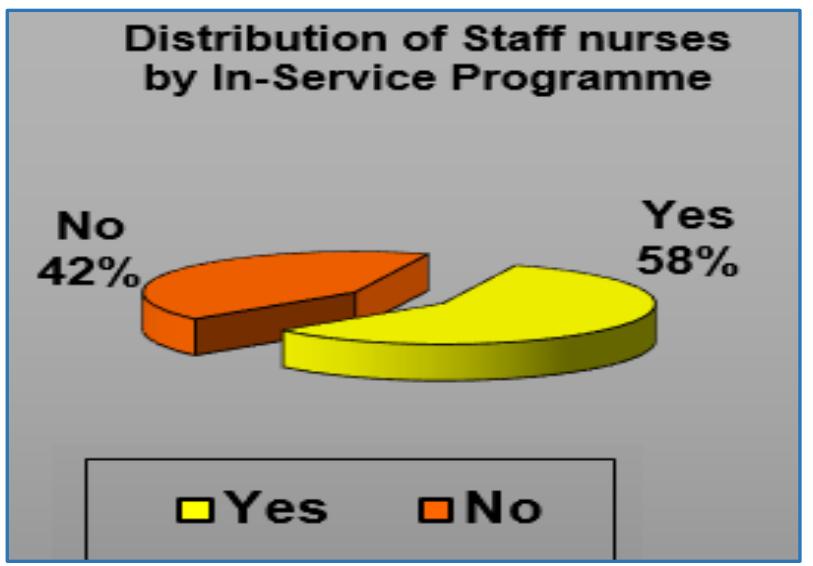

In this study, Majority 44 (88\%) of the respondents were females. Majority 20 (40\%) of the respondents belongs to the age group of 25-30 years. About 33 (66\%) of the subjects were married. Most $28(56 \%)$ of the respondents belongs to Christianity. All the respondents (50) had completed Diploma in General Nursing and Midwifery course. Majority 27 (58\%) of respondents were having 0 to 5 years of professional experience. Only 29 (58\%) of the subjects had attended In-Service Programme. Most 15 (30\%) of the subjects were working in antenatal ward.

\begin{tabular}{|c|c|c|c|c|c|c|}
\hline Sl. No. & Item & Max. Possible Score & Mean & SD & Range & Mean \% \\
\hline $\begin{array}{l}1 . \\
2 . \\
3 . \\
4 . \\
5 .\end{array}$ & $\begin{array}{l}\text { Knowledge } \\
\text { a. Definition \& meaning } \\
\text { b. Aetiology } \\
\text { c. Clinical features \& Diagnosis } \\
\text { d. Treatment } \\
\text { e. Nursing care }\end{array}$ & $\begin{array}{c}5 \\
5 \\
10 \\
10 \\
10 \\
\end{array}$ & $\begin{array}{l}1.18 \\
0.62 \\
1.98 \\
0.92 \\
3.54 \\
\end{array}$ & $\begin{array}{l}1.02 \\
0.95 \\
1.58 \\
1.96 \\
2.73 \\
\end{array}$ & $\begin{array}{l}0-3 \\
0-3 \\
0-8 \\
0-8 \\
0-9\end{array}$ & $\begin{array}{c}23.6 \\
12.4 \\
19.8 \\
9.2 \\
35.4 \\
\end{array}$ \\
\hline 5. & Overall Score & 40 & 8.22 & 6.73 & 1-29 & 20.55 \\
\hline \multicolumn{7}{|c|}{ Section-II: Table 2: Assessment of Knowledge of Pre-Test } \\
\hline
\end{tabular}

The Table 2, depicts that the summary of statistical outcome of knowledge on postnatal depression after administration of STP, i.e. pre-test knowledge scores. The overall pre-test knowledge score was found to be mean 8.22 with standard deviation 6.73 , mean score percentage was 40 and score ranges between 1 to 29 . Area wise analysis of pretest knowledge score was done, which shows that the knowledge score for definition and meaning mean score was 1.18 with SD 1.02 and mean score percentage was 5 and score ranges between 0 to 3 .
The knowledge score for aetiology mean score was 0.62 with SD 0.95 and mean score percentage was 12.4 and score ranges between 0 to 3 . The knowledge score for Clinical features and Diagnosis mean score was 1.98. With SD 1.58 and mean score percentage was 19.8 and score ranges between 0 8. The Knowledge score for Treatment mean score was 0.92 with SD 1.96 and Mean score percentage was 9.2 and score ranges between $0-8$. The knowledge score for nursing care mean score was 3.54 with SD 2.73 and mean score percentage was 35.4 and score ranges between 0-9. 


\begin{tabular}{|c|c|c|c|c|c|c|}
\hline Sl. No. & Item & Max. Possible Score & Mean & SD & Range & Mean\% \\
\hline $\begin{array}{l}1 . \\
2 . \\
3 . \\
4 . \\
5 .\end{array}$ & $\begin{array}{l}\text { Knowledge } \\
\text { a. Definition \& meaning } \\
\text { b. Aetiology } \\
\text { c. Clinical features \& Diagnosis } \\
\text { d. Treatment } \\
\text { e. Nursing care }\end{array}$ & $\begin{array}{c}5 \\
5 \\
10 \\
10 \\
10\end{array}$ & $\begin{array}{c}4.14 \\
3.6 \\
7.58 \\
6.98 \\
9.7 \\
\end{array}$ & $\begin{array}{c}0.95 \\
1.09 \\
2.14 \\
2.33 \\
0.7 \\
\end{array}$ & $\begin{array}{c}2-5 \\
2-5 \\
0-9 \\
2-10 \\
7-10\end{array}$ & $\begin{array}{c}82.8 \\
72 \\
75.8 \\
69.8 \\
97 \\
\end{array}$ \\
\hline & Overall Score & 40 & 32.16 & 6.26 & 14-39 & 80.4 \\
\hline
\end{tabular}

The Table 3 depicts that the summary of statistical outcome of post-test knowledge score on postnatal depression. The overall post-test knowledge score was found to be mean 32.16 with standard deviation 6.26; mean score percentage was 80.4 and score ranges between 14 to 39 . Area wise analysis of post-test knowledge score was done which shows that the knowledge score for definition and meaning, mean score was 4.14 with SD 0.95 and mean score percentage was 82.8 and score ranges between 2 to 5 . The knowledge score for aetiology mean score was 3.6 with SD 1.09 and mean score percentage was 72 and score ranges between 2 to 5 . The knowledge score for Clinical features and Diagnosis mean score was 7.58 with SD 2.14 and mean score percentage was 75.8 and score ranges between $0-9$. The knowledge score for Treatment mean score was 6.98 with SD 2.33 and mean score percentage was 69.8 and score ranges between 2 to 10 . The knowledge score for nursing care mean score was 9.7 with SD 0.7 and mean score percentage was 97 and score ranges between 7 to 10 .

\section{Section - III: Effectiveness of Structured Teaching} Programme

\begin{tabular}{|c|c|c|c|c|c|}
\hline Parameter & Mean & S.D & SEM & $\begin{array}{c}t- \\
\text { value }\end{array}$ & Result \\
\hline Pre-test & 8.22 & 6.73 & 0.95 & \multirow{3}{*}{31.59} & \multirow{3}{*}{$\begin{array}{c}\text { Highly } \\
\text { Signi- } \\
\text { ficant } \\
\mathrm{P}<0.001\end{array}$} \\
\hline Post-test & 32.16 & 6.26 & 0.89 & & \\
\hline $\begin{array}{l}\text { Improve- } \\
\text { ment }\end{array}$ & 23.94 & 0.47 & 0.06 & & \\
\hline & 1 & & & ess & uctured \\
\hline
\end{tabular}

The mean pre-test value is 8.22 , standard deviation is 6.73 and standard mean error is 0.96 . The mean score is increased in the post test. The mean in the post test is 32.16 and the standard deviation is 6.26. Standard error of mean is 0.89 . The gain in the knowledge based on difference in the pre-test and post-test mean was found to be 23.94 (Improvement). The calculated ' $t$ ' value is 31.59 , which are highly significant $(\mathrm{P}<0.001)$. The results proved that the structured teaching programme was effective in improving the knowledge of staff nurses regarding post natal depression.

Section-IV: Association between the Level of Knowledge and Socio-Demographic Characteristics

\begin{tabular}{|c|c|c|c|c|c|}
\hline $\begin{array}{c}\text { Sl. } \\
\text { No. }\end{array}$ & $\begin{array}{c}\text { Characteri- } \\
\text { stics }\end{array}$ & $\begin{array}{c}\text { Chi- } \\
\text { square } \\
\text { value }\end{array}$ & Df & $\begin{array}{c}\text { P- } \\
\text { Value }\end{array}$ & Result \\
\hline 1 & Age & 18.2 & 4 & $<0.001$ & $\begin{array}{c}\text { Highly } \\
\text { Signi- } \\
\text { ficant }\end{array}$ \\
\hline 2 & Gender & 0.434 & 1 & $>0.05$ & NS \\
\hline 3 & $\begin{array}{c}\text { Intensive } \\
\text { programme }\end{array}$ & 7.24 & 1 & $<0.05$ & Significant \\
\hline
\end{tabular}

\begin{tabular}{|c|c|c|c|c|c|}
\hline 4 & $\begin{array}{c}\text { Current } \\
\text { working area }\end{array}$ & 17.5 & 8 & $<0.05$ & Significant \\
\hline 5 & $\begin{array}{c}\text { Experience in } \\
\text { years }\end{array}$ & 12.3 & 4 & $<0.05$ & Significant \\
\hline 6 & Religion & 2.81 & 2 & $>0.05$ & NS \\
\hline 7 & $\begin{array}{c}\text { Marital } \\
\text { Status }\end{array}$ & 0.84 & 2 & $>0.05$ & NS \\
\hline \multicolumn{5}{|c|}{ Table 5: Association of Results with Demographic } \\
Characteristics
\end{tabular}

The table shows among all demographic data, Age is highly significant. Gender, Marital status and Religion are not significant. Intensive programme, current working area and experience in years are significant, whereas the Qualification cannot be calculated.

\section{DISCUSSION}

The mean pretest knowledge is 8.22 . The mean post-test percentage knowledge score was 32.16 , which was higher than the mean pretest percentage score. The mean pretest values is 8.22 and mean post-test value is 32.16 . The mean difference between pretest and post-test is 23.94 . There is a significant difference between the pre and post-test knowledge scores of staff nurses regarding postnatal depression at 0.05 level of significance. The findings with regard to pre-test knowledge on postnatal depression revealed that the knowledge of RNs regarding postnatal depression was inadequate. These findings highlight the need for teaching programmes to improve knowledge of staff nurses in postnatal depression.

Some studies on knowledge of nurses on postnatal depression show that there is need to improve the Knowledge and Skills in identifying symptoms and giving prompt treatment. Study conducted by Jones CJ ${ }^{1}$, Creedy DK, Gamble $\mathrm{JA}^{10}$ on eight hundred and fifteen members of the Australian College of Midwives stated that about the question on postnatal depression correctly answered $62.9 \%$ of items related to antenatal depression and $70.7 \%$ of questions about postpartum depression, unable to identify the risk factors $(70.6 \%)$ or prevalence of antenatal depression $(49.6 \%)$. Significant percentages of midwives did not correctly identify the incidence (44.4\%), onset period $(71 \%)$ and treatment options (32\%) associated with postpartum depression. About half did not understand the use of antidepressant medications (48.6\%) and incorrectly reported that the Edinburgh Postnatal Depression Scale was a suitable instrument to assess symptoms of psychotic depression (43.8\%). They also concluded that there is a need for continuing professional education to improve midwives' knowledge and competency in the assessment and care of women suffering from depression. Another study by Işık S. N.; Bilgili N11 stated that majority of midwifes do not know the definition of depression $(84.4 \%)$, risk factors for it $(73.4 \%)$ and the methods of diagnosing it (72.2\%). 
The findings of study demonstrate that the information and practice of nurses and midwives are not at the expected level. It may be recommended that the awareness of the midwives and nurses is enhanced by informing on the subject for diagnosing and suitable intervention on PND in early period. Studies related to effectiveness of structured teaching programme shows similar results. Study by Shrikant Desai, 12 Ujwala A Chopade,13,14 Prakash M Naregal15,16 and Prabhuswami Hiremath. ${ }^{17}$ proved that STP could be an effective mean for improving the knowledge.

\section{CONCLUSION}

There is a statistically significant improvement in the knowledge among the staff nurses who underwent the structured teaching program on post-natal depression.

\section{ACKNOWLEDGEMENT}

Author is thankful to the Principal of the Institution and Hospital Authority for the support given during the study.

\section{Implications}

The findings of the study have several implications for nursing service, nursing education and nursing research

\section{Nursing Service}

The findings of the study could be utilized as a basis for orientation programmes and in-service education of the nurses, so that constant awareness and clear understanding may be created regarding postnatal depression. This will increase the knowledge and practices of RNS regarding various aspects of postnatal depression.

\section{Nursing Education}

The nurse educators have the responsibility to update the knowledge of RNs and thereby improve their knowledge through various educational programmes. In India the existing nursing curriculum includes content on postnatal depression. But the updated guidelines can be incorporated in the curriculum.

\section{Nursing Administration}

Nursing administration should take initiative to conduct orientation program for advanced beginners. They must make sure that In-Service Education Program are conducted periodically. After training, the nurses should be provided with adequate facilities and supervision to maintain the standards of knowledge on postnatal depression.

\section{Nursing Research}

Today Nurses are actively generating, publishing and applying research in practice to improve client care and enhance scientific knowledge base of Nursing.

The study throws light on the area of nurses' knowledge regarding postnatal depression. There is a lot of scope for exploring this area. Research can be done on the factors related to postnatal depression, its identification and prevention and treatment.

\section{REFERENCES}

1. Fraser DM, Cooper MA. Myles textbook for midwives. $14^{\text {th }}$ edn. Edinburgh: Churchill Livingstone 2003:p. 659.

2. Wong, Hockenberry, Wilson, et al. Maternal child nursing care. $3^{\text {rd }}$ edn. China: Mosby Elsevier 2006:p. 674.

3. Patel V, Rodrigues M, DeSouza N. Gender, poverty, and postnatal depression: a study of mothers in Goa, India. American Journal of Psychiatry 2002;159:43-47.
4. Hiremath $\mathrm{P}$, Mohite VR, Naregal P, et al. A study to determine the prevalence of postnatal depression among primigravida mothers in Krishna hospital Karad. International Journal of Science and Research 2015;4(2):247-249.

5. Leahy-Warren P, McCarthy G, Corcoran P. Postnatal depression in first-time mothers: prevalence and relationships between functional and structural social support at 6 and 12 weeks postpartum. Arch Psychiatr Nurs 2011;25(3):174-84. www.sciencedirect.com.

6. Leahy-Warren P, McCarthy G. Postnatal depression: prevalence, mothers' perspectives, and treatments. Archives of Psychiatric Nursing 2007;21(2):91-100.

7. Crotty F, Sheehan J. Prevalence and detection of postnatal depression in an Irish community sample. Irish Journal of Psychological Medicine 2004;21(4):117-121.

8. Grier G, Geraghty S. Mind matters: developing skills and knowledge in postnatal depression. British Journal of Midwifery 2015;23(2):10-14.

9. Jones CJ, Creedy DK, Gamble JA. Australian midwives awareness and management of antenatal and postpartum depression. Woman Birth 2012;25(1):23-28.

10. Jones CJ, Creedy DK, Gamble JA. Australian midwives knowledge of antenatal and postpartum depression: a national survey. Journals of Midwifery Women's Health 2011;56(4):353-61.

11. Işılk SN, Bilgili N. Postnatal depression: midwives and nurses knowledge and practices. Erciyes Tip Dergisi 2010;32(4):265-274.

12. Desai S, Hiremath P, Naregal P. A study to assess the effectiveness of planned teaching programme on knowledge regarding epilepsy management in school children among primary school teachers working in selected primary schools at Malur, Kolar, Karnataka. International Journal of Health Sciences and Research 2015;5(8):417-423.

13. Chopade UA, Kadam S, Hiremath P. A Study to assess the effectiveness of planned teaching programme (PTP) on knowledge regarding needle stick, sharp injuries and their prevention among 1st year B. Sc. nursing students at KINS, Karad. International Journal of Health Sciences and Research 2015;5(8):401-406.

14. Chopade U, Mohite VR, Salunkhe A, et al. A study to assess the effectiveness of self-instructional module on the knowledge of prevention of nosocomial infection among $2^{\text {nd }}$ year RGNM students of Krishna institute of nursing sciences at Karad. International Journal of Innovative and Research 2016;5(5):59-63.

15. Naregal PM, Mohite VR, Hiremath P, et al. Effectiveness of planned teaching programme on knowledge regarding prevention of child abuse and neglect among primary school teachers. Online Journal of Health Allied Sciences 2015;14(4):11.

16. Naregal PM, Mohite VR, Hiremath P, et al. Effectiveness of SIM (Self Instructional Module) on knowledge regarding prevention of nosocomial infection in NICU among nursing students. IJHSR 2015;5(4):190-196.

17. Hiremath $P$, Mohite VR, Naregal P, et al. A study to assess the effectiveness of planned teaching programme on knowledge and management of epilepsy among epileptics attending outpatient department in Krishna hospital Karad. IJHSR 2014;4(10):172-176. 